\title{
DGB Neo-Freudian-Neo-Psychoanalysis: A Preliminary Communication on the Different Types and Expressions of Sub-Clinical and Clinical Paranoia
}

Received: June 06, 2017; Accepted: June 20, 2017; Published: June 30, 2017

Capitalism - at least manipulative, unethical, narcissistic Capitalism - breeds paranoia. But that is the subject of an essay that I may never write. Instead, the type of paranoia that I am interested in here can be called 'Oedipal Transference Paranoia' - meaning that it is learned early in childhood and may find full - and different types of - expression later in life. 'Defensive expressions'. And 'phantasy expressions' - meaning in dreams, and in extreme cases - 'psychotic paranoia' or 'paranoidschizophrenia' (or whatever the present DSM labels might be).

Paranoia is born in distrust - meaning a sense of emotional betrayal, abandonment, neglect, detachment, rejection, etc. But what separates distrust from paranoia is the sense of 'legitimacy' in 'legitimate distrust' vs. the 'interpretive informal or formal diagnosis by outside observers' - friends, family, therapists (or even 'self-diagnosis') - what needs to be made clear here is that there is no '100 percent right or wrong diagnosis' here - it's like the word 'abuse' - sometimes the word 'abuse' is abused and can cause more problems just by the label and the stereotype than no diagnosis at all.

Where lays the boundary between legitimate and illegitimate distrust? The boundary between legitimate distrust and paranoia.

For what it is worth, we can call paranoia - 'over-generalized distrust'. And thus, it can generate 'cognitive-emotionalbehavioral problems' - more problems than the paranoia is worth - or 'solves' in terms of 'not being burned upon being led down a garden path - with no garden but perhaps a deep mud-hole'. We all think like this at different times depending on the context of the situation and who we are dealing with - the 'paranoid' person simply does this type of 'pessimistic, cynical, distrustful thinking' - more often.

Thus, we come to what I call 'Oedipal Serial Transference Paranoia' which is 'born in the Oedipal Period of Psychical Development' (2 to 7 years old).

In this regard, we can distinguish 'Oedipal Serial Transference Paranoia' - paranoia that started with 'mom' or 'dad' or substitute 'Oedipal Period Caretakers' - from 'Oedipal Period Serial Transference Paranoia' which might have started from a sibling, a relative, or even a random stranger. And in both

\section{David Gordon Bain*}

David Gordon Bain, DGB Integrative Wellness and Education Services, Ontario, Canada

\author{
*Corresponding author: \\ David Gordon Bain
}

\section{dgbainsky@yahoo.com}

David Gordon Bain, DGB Integrative Wellness and Education Services, 517 Winkworth Crt, Newmarket, Ontario, Canada.

Tel: $289-879-7868$

Citation: Bain DG (2017) DGB NeoFreudian-Neo-Psychoanalysis: A Preliminary Communication on the Different Types and Expressions of Sub-Clinical and Clinical Paranoia. J Hosp Med Manage. Vol. 3 No. 1: 8

cases, we need to distinguish the difference between 'Memory Oedipal Transferences' as opposed to 'Relationship Oedipal Transferences' - the difference between a remembered 'onetime encounter' vs. the memory of an 'Oedipal Period Ongoing Relationship'.

At this point, we need also to distinguish between 'conditional' and 'unconditional' love. If a child is raised in an environment where he or she feels 'unconditionally loved' - or close to it - this is the type of environment that is likely to foster a 'more stable sense of self-esteem'.

In contrast, if a child feels criticized almost all the time and/or is brought up to believe that love is 'conditional upon a certain type and/or threshold of performance' - well, depending on 'how well or how poorly the child performs' - and often regardless of either or both possible scenarios - the child may start to feel like he or she is 'walking on pin and needles or eggshells' - with an increased sense of internal stress and stress hormone production. This is not conducive to good health. Or a sense of 'parent-child trust' and the reverse which lays the groundwork for what I am calling 'Oedipal or Oedipal Period Paranoia - either the one time encounter type, and/or the ongoing relationship type.

Now, the Pre-Oedipal Transference Psychoanalysts - who generally tend to be 'Object Relations' theorists/analysts - focus 
on the period between birth (or even before birth) and about 2 years old, whereas, I focus, as described above, mainly on the Oedipal years of about 2 to 7 years old - and 'the Oedipal Transferences' arising from this time period that get 'locked away' - but remembered acutely, either consciously or unconsciously in our 'Oedipal Transference Templates'.

Now, for the purpose of classification, Freud, in his last major paper in 1938 (Outline of Psychoanalysis), stated that there is a period of early childhood development - Freud did not say when - where the 'ego' and 'id' are 'undifferentiated' as what Freud himself called 'the ego-id' (or 'id-ego' which I like better).

There is a point here where Psychoanalysis (or NeoPsychoanalysis) meets Neurology as, from my perspective, the 'Id and Oedipal Complex Templates' meet 'The Limbic System of The Brain' and some of its different sub-parts such as the amygdala that are connected to emotional memories, retrieval, and motivation - both positive and negative relative to these 'highly charged' memories - Freud and Strachey used to call these types of memories 'emotionally cathected memories'. So highly charged emotional memories - both positive and negative - become 'trigger points' 'associated here-and-now scenes' (or alternatively, the here and now scenes become 'trigger points' for the sudden recollection of 'highly charged emotional memories from the past - particularly, the Oedipal Period Past.

In this regard, the Pre-Oedipal and Oedipal Templates become the foundation for character structure and personality development
- from a theoretical point of view, 'Personality Theory' as well as what I am beginning to develop here: specifically, 'SubPersonality-Ego-State Theory'.

In this regard, I know that Freud's 'Psycho-Sexual Stages of Development' have been mainly discarded by present-day analysts and theorists. However, I bring this classification system by Freud back alive again under the heading of 'Psycho-Social EgoStates of Existence'. Now I am back up to a 20 part classification system that can be 'downsized' or 'upsized'.

For our purposes here, I will identify 6 different possible 'paranoid' ego-states:

Paranoid-psychotic; Paranoid-violent; Paranoid-verbally confrontational; Paranoid-passive-aggressive; Paranoid-schizoid; Paranoid-schizoid-depressive.

All are built on 'over-generalized distrust - blown out of all reasonable proportion'.

If you are working with a 'paranoid person' (of sub-clinical and/ or clinical proportions) - and you want to keep your 'therapeutic alliance' alive, it may seem obvious, but you will probably want to do the best you possibly can to 'steer clear of the person's paranoid ego-states' - or 'back up' and try to 're-establish trust' if or when you do; otherwise, you are likely to be met with a 'wall of defensive resistance' that will probably put an end to all possible 'therapeutic gain' unless or until trust is re-established. 